\title{
Os Ciganos Vistos pelos Outros Coexistência Inter-Étnica em Espaços Urbanos
}

\author{
Alexandra Castro * \\ Isabel Duarte ** \\ Joana Afonso ** \\ Mafalda Sousa ${ }^{* * *}$ \\ M. J. Lobo Antunes ***** \\ Margarida Salgueiro ${ }^{\text {****** }}$
}

\begin{abstract}
$\mathrm{R}$ umo: 0 presente artigo sintetiza os principais resultados da investigação "Coexistência inter-étnica, espaços e representações sociais: os ciganos vistos pelos outros". Esta pesquisa incidiu sobre a comunidade cigana em três espaços de co-presença (espaços residencial, profissional e ocasional), numa tentativa de compreender em que medida as práticas e as representações sociais que os não-ciganos tinham sobre os ciganos - práticas e representações sociais marcadas por (des)encontros de natureza esporádica e/ou quotidiana - variavam em função da natureza de cada espaço.
\end{abstract}

Palavras-chave: ciganos; comunidade; espaço; representações sociais; coexistência inter-étnica; relações inter-étnicas; raça e racismo.

"(...) we are not aware of the distinctiveness and the circumscription of our own behaviour until we meet its normative boundaries in the shape of alternative forms."

Anthony Cohen

\section{Introdução}

Este artigo pretende dar conta dos principais resultados obtidos no decurso de uma investigação ${ }^{1}$ cujo objectivo fundamental era compreender e analisar as representações existentes sobre a comunidade cigana em contextos de co-presença com não ciganos. Subjacente a este propósito estava a ideia de que o confronto com as fronteiras - apreendidas enquanto formas de comportamento alternativas, como afirma Cohen (1985) - constitui o momento fundamental do processo de negociação das identidades sociais. É através deste confronto que se constroem auto-imagens e, por oposição e distinção, as imagens da alteridade.

Para isso, escolheram-se espaços-situação em que estes dois universos (ciganos e não-ciganos) se encontrassem de uma forma esporádica ou quotidiana: o espaço residencial, o espaço de exercício profissional e o espaço de permanência ocasional junto de equipamentos colectivos ${ }^{2}$.

\footnotetext{
* Socióloga, Investigadora do CET. Contacto: Alexandra.I.Castro@seg-social.pt

** Assistente no ISCTE, Investigadora do CET. Contacto: isabel.duarte@iscte.pt

*** Antropóloga, Colaboradora do CET. Contacto: jafonso@ socleo.pt

**** Colaboradora do CET na área da Sociologia. Contacto: mafalda.m.sousa@clix.pt

***** Assistente no Departamento de Antropologia da Universidade de Coimbra. Contacto:zloboantunes@yahoo.com

****** Colaboradora do CET na área da Antropologia. Contacto: guiguisalgueir•@yahoo.com

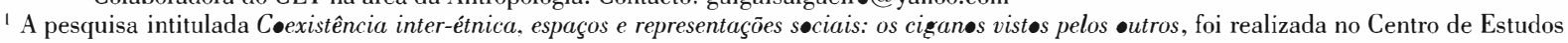
Territoriais entre Outubro de 1999 e Dezembro de 2000, coordenada por Isabel Duarte e financiada pela Fundaçāo para a Ciência e Tecnologia, no âmbito de um concurso promovido pelo Alto Comissário para a Imigraçāo e Minorias Étnicas.

${ }^{2} \mathrm{O}$ espaço residencial englobou dois estudos de caso distintos: (a) um contexto de uma convivência quotidiana num bairro de habitaçāo social onde coabitam diversos grupos étnicos e (b) um contexto de permanência casual de acampamentos de ciganos nómadas. $\mathrm{O}$ estudo do espaço de exercício profissional foi realizado numa feira, implicando um contacto regular entre feirantes (ciganos e nāo-ciganos), clientes e agentes de entidades de supervisāo, contacto esse delimitado no tempo (as horas em que a feira se encontra em funcionamento) e na natureza das interacções geradas (enquadradas no âmbito profissional). O espaço de permanência ocasional junto de equipamentos colectivos foi contemplado pelo estudo de caso de um hospital, onde se encontram profissionais de saúde, os utentes e as suas famílias, num cenário de doença, sofrimento e morte. Refira-se que se revelou impossível apresentar apenas num artigo todos os resultados decorrentes da referida investigaçâo. Desta forma, o próximo número da revista "Cidades. Comunidades e Territórios", dedicado à temática da habitaçāo, será um momento oportuno para a apresentaçāo mais aprofundada dos estudos de caso relativos ao espaço residencial de co-presença entre ciganos e nāo-ciganos.
} 
A questão básica a que se pretendia dar resposta equacionava, por um lado, as particularidades físicas e sociais de cada um dos espaços seleccionados e, por outro lado, a natureza das interacções e representações desenvolvidas no seu interior. De facto, importava compreender não apenas de que modo se constroem as representações sobre a comunidade cigana em cenários de proximidade física, mas também proceder a uma análise comparativa da especificidade das representações em cada um dos espaços-situação estudados.

Para uma compreensão das grandes linhas de discussão e questionamento presentes no desenvolvimento da pesquisa, seleccionaram-se como referenciais teóricos os conceitos de raça e racismo, de representações sociais, de comunidade e de espaço público.

\section{Raça e Racismo}

Sabendo que a ideia de "raça" não tem qualquer correspondência objectiva nas ciências naturais e que é peremptoriamente posta de parte enquanto conceito operacional validado cientificamente, resta-nos interrogar sobre o porquê da sua sobrevivência. Muitos autores apontam o dedo aos responsáveis pela construção da teoria social ao considerarem ilegítimo o uso do termo raça (e até mesmo racismo) pelas ciências sociais. Apesar da perpetuação da tradição anglo-saxónica no uso de termos como "racial studies" ou "race relations" , os teóricos não são alheios às dificuldades da sua conceptualização. Não poucos advogam a supressão da ideia de raça alegando terem responsabilidades acrescidas na formação da opinião pública. A questão ética põe-se na prática ao julgar-se que a não utilização de tais terminologias faz desaparecer as suas consequências funestas.

Se a nossa posição é, obviamente, de discordância total dos determinismos biológicos, não somos, no entanto, alheios aos fenómenos presentes na vida social sejam eles construídos com base em dados objectivos ou em ficções, melhor dizendo, "o que é central para as ciências sociais é o facto de os indivíduos nas suas interacções quotidianas aceitarem as 'raças' como realidades; isso torna-as subjectivamente reais" (Marques, 1997: 66).
Como construção social a noção de raça faz-se depender dos contextos sociais, históricos / geográficos e culturais onde é operacionalizada quotidianamente pelos actores sociais. Para ilustrar a sua vulnerabilidade situacional o exemplo mais referido é de que devido à diferença de classificações raciais um indivíduo tido como 'negro' nos Estados Unidos pode ser considerado 'branco' no Brasil.

\section{Racismos}

O racismo, forjado terminologicamente na palavra raça, aparece progressivamente mais distante das concepções que estiveram na sua origem. A viragem nos discursos sobre a diferença é manifestamente visível nas reacções ao holocausto nazi enquanto materialização evidente e cruel das práticas discriminatórias alicerçadas nas ideias de superioridade e pureza raciais.

A par dos discursos oficiais, a linguagem corrente do senso comum adopta discursos onde a tónica da construção do Outro é transferida da dimensão racial para a dimensão cultural (também ela reificada). É notória a substituição do termo raça para o de etnia, de categorias raciais para minorias étnicas, numa tentativa de despojamento de conotações negativas ligadas a fenómenos históricos como a escravatura, a dominação colonial, a exploração económica e pressão política e, em última análise, a supressão física do Outro.

$\mathrm{Na}$ tentativa de operacionalizar as duas dimensões ideológicas (diferenciação e inferiorização biológica e diferenciação e inferiorização cultural) na investigação empírica sobre o racismo, este é dividido em racismo flagrante e racismo subtil (cf. Vala,1999). O primeiro manifesta-se ao nível dos comportamentos abertos de discriminação e agressão física ou psicológica (é quente, próximo e directo), enquanto que o segundo se baseia na ideia de hierarquia cultural como preditor das diferenças qualitativas: "o endogrupo é melhor que o exogrupo" (é frio, distante e indirecto), (idem 1999).

A crítica mais directa a estas novas definições de racismo centra-se no perigo de inflação conceptual do racismo que conduzem à crença na omnipresença do racismo em todas as instâncias formais e informais da vida social,

${ }^{3}$ Da bibliografia utilizada para esta breve reflexão destacam-se duas referências muito recentes cujos títulos são elucidativos: Bulmer e Solomos 1999, Back e Solomos, 2000. 
originando uma indefinição do racismo enquanto "objecto sociológico de reflexão e de pesquisa sociológica" (Machado, 2000: 22).

O desdobramento do conceito de racismo, enquanto prática social, em racismo institucional e racismo individual apresenta um novo problema de definição. Às práticas discriminatórias individuais e de grupo relativamente ao "Outro racializado" sobrepõe-se a ideia do racismo instituído na estrutura social. Se consideramos que estamos perante uma inflação da ideia de racismo institucional não podemos negar que este tipo de racismo assume, pelo menos, formas institucionais ainda que difusas, encobertas ou indirectas no contexto de modelos normativos anti-racistas.

É ao nível do discurso produzido sobre a comunidade cigana em vários contextos de co-presença que podemos reflectir sobre a enunciação de possíveis representações e práticas racistas. As três dimensões do racismo (ideologia, preconceito e discriminação) serão avaliadas, num palco privilegiado de proximidade física, no interior de processos de construção e reprodução social da diferença, alimentados (ou não) por uma dimensão conflitual. Numa análise mais fina, procuraremos uma possível "narrativa racial escondida" por uma linguagem discursiva alusiva à cultura e nação (Goldberg, 2000).

\section{Representações Sociais}

Na década de 60 surgiu uma nova teoria na psicologia social que gradualmente se expandiu e quebrou as fronteiras que a separavam das outras ciências afins. Essa nova teoria, delineada inicialmente por Moscovici (1984) e cujo conceito e objecto de estudo essencial era constituído pelas 'representações sociais', propunha um olhar original sobre paisagens já familiares, procurando revelar o seu dinamismo e criatividade. A introdução deste conceito gerou um novo equilíbrio entre dois grandes eixos de problematização nas ciências sociais (conhecimento/acção e indivíduo/sociedade), visto ter apresentado o indivíduo como sujeito-actor indissociável dos laços sociais em que se insere (Vala,1993). Abriu-se assim a possibilidade uma outra síntese entre psicologia e sociologia, na qual o indivíduo aparece dotado de uma vontade e capacidade de acção própria, como um sujeito pensante, e simultaneamente imbuído de traços provenientes da sociedade que o envolve.

Moscovici procurou sublinhar a natureza plural e dinâmica das representações sociais e abdicar da visão homogénea e coerciva que Durkheim havia defendido ${ }^{4}$. As representações sociais habitam num mundo plural e dinâmico, e longe de serem sistemas fechados e imutáveis, constituem "(...) a network of interacting concepts and images whose contents evolve continuously over time and space." (Moscovici, 1988: 220). Visto não constituírem imposições do exterior, elas resultam essencialmente dos processos de comunicação e interacção entre os homens e grupos, sendo essenciais os vários contributos individuais incorporados nesse mundo de conhecimento comum.

Os processos de comunicação desempenham um papel fundamental na criação, reprodução e transformação das representações sociais. Através deles o pensamento desenvolve-se como uma prática performativa, pois implicam a existência de uma audiência perante a qual as palavras e proposições proferidas comportam mais do que o seu significado imediato, reenviando para um universo comum de sentidos múltiplos implícitos. As representações sociais permitem a construção de uma linguagem comum, a partilha de uma rede de significados não expressos e a possibilidade da apreensão de certos elementos que concedem coerência aos discursos e às práticas sociais.

As representações sociais operam no quadro dos "universos consensuais" (Moscovici, 1984: 20) através de uma constante "dinâmica de familiarização", traduzindo os aspectos estranhos em formulações inteligíveis. No decurso deste processo, são accionados dois mecanismos ancoragem e objectivação -, que manipulam as memórias e experiências, transmudando dados indecifráveis em elementos claros e quase tangíveis. Dado que a realidade é essencialmente inapreensível, a função destes processos é a de procederem a uma adequação sistemática dessa mesma realidade às imagens que sobre ela se constróem. Deste modo, desenha-se o mundo fictício em que vivemos e ao qual atribuímos uma existência concreta.

\footnotetext{
${ }^{4} \mathrm{O}$ conceito de representação social resultou de uma reformulação da ideia durkheimiana de "representação colectiva" e da sua adequação ao mundo contemporâneo. A representação colectiva de Durkheim aplicava-se essencialmente às sociedades ditas tradicionais ou primitivas, onde supostamente reinava a homogeneidade e indiferenciação individual. Nestes casos, a conformidade da consciência do indivíduo aos desígnios colectivos era quase total. As eventuais trocas entre estes dois níveis seguiriam apenas um único sentido (do social para o individual), e implicariam uma relação de causalidade unívoca.
} 
As representações sociais, ao reportarem-se aos conteúdos do pensamento e ideias da vida quotidiana, concedem coerência à realidade que o homem observa e em que vive, e condicionam a sua percepção do mundo exterior. Devido ao seu carácter quase omnipresente e ao contínuo comentário que produzem e reflectem sobre a realidade, o seu papel pode ser comparado ao do coro das tragédias gregas (Moscovici, 1984: 21). Em todos os nossos movimentos, pensamentos e acções é possível encontrar um rasto da sua passagem, ainda que essa presença possa escapar a um olhar pouco atento.

\section{Comunidade}

O termo comunidade constitui um conceito central das ciências sociais. Para alguns autores, a sua importância é tão grande que não hesitam em considerá-lo o "mais fundamental dos conceitos elementares" do pensamento sociológico (Nisbet, 1966). No entanto, e apesar da sua centralidade, o conceito de comunidade tem permanecido envolto numa nuvem de confusão. Em seu redor existe uma tremenda dificuldade de consenso, já que este termo tem sido utilizado para descrever e analisar diferentes realidades, de acordo com diversas perspectivas teóricas e procedimentos metodológicos.

Da análise levada a cabo por Hillery (cit. por Bell e Newby, 1971), reencontramos essencialmente três elementos definidores do conceito: a interacção social, a área geográfica e a existência de laços sociais de uma natureza particular. Em alguns casos, estes elementos sobrepunham-se, desenhando um conceito de comunidade multidimensional; noutros, pelo contrário, apenas um deles bastava para criar uma definição operacional do conceito ${ }^{5}$.

Para vários autores, a confusão e polémica que existe em torno do conceito de comunidade pode ser em parte explicada pela quase impossibilidade de um sociólogo falar de comunidade sem referir ou introduzir a sua perspectiva pessoal sobre o tema. Segundo Colin Bell e Howard Newby, os sentimentos (obviamente subjectivos) associados à palavra comunidade fazem com que se confunda frequentemente o que a comunidade é (a sua descrição empírica) com aquilo que o sociólogo pensa que deveria ser (descrição normativa) (Bell e Newby, 1971: 21).
No mesmo sentido, Joseph Gusfield retoma a distinção entre o sentido semântico e o sentido poético das palavras, aplicando-a à ideia de comunidade. $\mathrm{O}$ sentido semântico tem um valor falso ou verdadeiro: designa uma coisa de uma forma que todas as pessoas podem utilizar e compreender, procurando a clareza e a erradicação de significados emotivos. Implica, por isso, a "discussão de acontecimentos humanos e sociais num vocabulário não moral" (Gusfield, 1975: 85). Pelo contrário, o sentido poético implica a adopção de uma atitude perante o objecto/sujeito designado. Segundo Gusfield, o conceito de comunidade deve ser visto como simultaneamente poético e semântico: para além do seu significado objectivo e neutral, ele tem implicado também uma descrição idealizada de uma organização social da qual nos estaríamos a afastar, mas para a qual deveríamos regressar.

$\mathrm{O}$ conceito de comunidade, desenvolvido nas ciências sociais desde o século XIX, está indelevelmente preso ao que Robert Nisbet chama de "novas utopias", ancoradas nos presumíveis laços profundos e incondicionais que uniriam o homem aos seus companheiros e à sua comunidade (Nisbet, 1966). Os autores clássicos que desenvolveram o conceito de comunidade transmitiam uma imagem ideal de sociedade, presumivelmente perdida com as transformações sociais e económicas, condenada ao desaparecimento total. Nas palavras de Worsley, “(...) a transformação do «velho» para o «novo» na sociedade foi concebida frequentemente como um processo de desorganização social que compreende a erosão e, por vezes, até o desaparecimento da vida em comunidade." (Worsley, 1970 :349). Assim, nesta ideia de comunidade cabiam elementos tão diversos como as relações sociais estreitas e íntimas, a extrema importância da família, Igreja e comunidade local, a importância da solidariedade e união, o compromisso de natureza moral e adesão comum a um grupo social e, finalmente, a importância central do passado e da tradição.

Esta ideia de comunidade foi quase sempre apresentada numa perspectiva dicotómica. Contraposta à comunidade, aparecia o seu "negativo" - a "não-comunidade" - caracterizada pela atomização, isolamento, insegurança. $\mathrm{Na}$ "não-comunidade" as relações sociais basear-se-iam na ideia de contrato e já não nas relações sólidas

${ }^{5}$ Para uma revisão das diversas conceptualizações do termo comunidade, ver Bell e Newby 1971, Clark 1973, Cohen 1985, Worsley, 1970. 
e afectivas do parentesco e da amizade. A sociedade estaria, por isso, virada para o futuro e para a concretização de objectivos estabelecidos individualmente ${ }^{6}$.

A perspectiva dicotómica de comunidade pode ser vista como a que opõe as relações baseadas em sentimentos (ligações emocionais e intrínsecas) daquelas baseadas em interesses (objectivos partilhados que prevêem a cooperação como meio de se atingir os fins pretendidos). Esta perspectiva, mais do que apenas encerrar con-

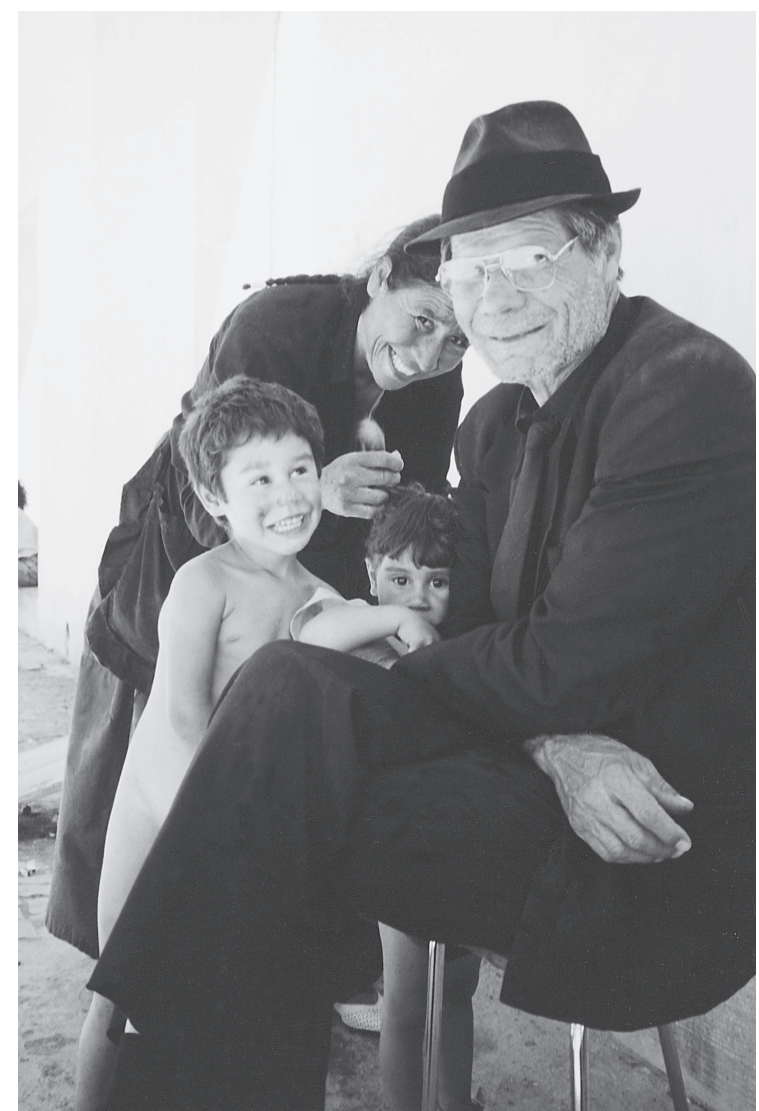

Foto de Alexandra Castro

ceitos puros, contém em si uma teoria da mudança social: do simples para o complexo, do íntimo para o impessoal, da união e solidariedade para a fragmentação e competição.

\section{Construção Simbólica da Comunidade}

Procurando ultrapassar as muitas e infindáveis discussões teóricas que rodeiam este conceito nas ciências sociais, optámos por uma abordagem que procura compreender os mecanismos que, de uma forma essencialmente simbólica, criam e mantêm as fronteiras entre grupos sociais. Neste sentido, recorremos à definição de comunidade proposta por Anthony Cohen. Segundo este autor, a ideia de comunidade não deve ser compreendida pelo seu sentido lexical, mas sim através do uso. Assim sendo, comunidade implica, simultaneamente, similitude e diferença, já que é empregue para designar um grupo social cujos membros se encontram unidos por traços comuns que, por outro lado, os distinguem de outros grupos ou entidades sociais (Cohen, 1985: 12).

A definição proposta por Cohen pretende ultrapassar o impasse que rodeia o conceito de comunidade nas ciências sociais. A exclusão da referência a elementos tradicionalmente utilizados na construção do conceito - como o território, a língua ou a religião - tem como objectivo fundamental apreender o "sentido experiencial da pertença" à comunidade. Isto porque, para Cohen, a comunidade deve ser compreendida como o "sentido da primazia da pertença": comunidade é aquela entidade a que se pertence, maior do que o parentesco, mas mais pequena do que a abstracção a que chamamos sociedade; comunidade é onde se aprende e onde se continua a praticar ao longo da vida o «ser social» (Cohen, 1985: 15).

A adopção de um conceito cuja definição não faz apelo a traços demasiado específicos (território, religião, língua, etc.) tem uma mais-valia essencial na presente investigação: a extrema flexibilidade na sua operacionalização. Mais do que a imposição apriorística de elementos definidores do que será (ou não) a comunidade cigana, o recurso à definição de comunidade proposta por Cohen permite-nos compreender de que forma se constrói esta comunidade aos olhos dos não-ciganos. Esta foi, de facto, uma das preocupações fundamentais na componente empírica do trabalho: apreender as representações sobre os ciganos, os seus traços definidores e as práticas sociais específicas desta comunidade, vista a partir do exterior.

De acordo com Cohen, as comunidades não existem em si mesmas, isoladas do mundo que as rodeia. Pelo contrário, a sua existência é o resultado de um processo de natureza essencialmente

\footnotetext{
${ }^{6}$ Autores clássicos da teoria social como Ferdinand Tonnies (comunidade/sociedade), Émile Durkheim (solidariedade mecânica e solidariedade orgânica), Henry Morgan (societas/civitas) ou Lewis Maine (estatuto/contrato) são alguns exemplos da construção dicotómica do conceito de comunidade (cf. Cohen 1985, Gusfield ,1975, Nisbet, 1966).
} 
relacional. É através do confronto com a alteridade que se constroem, por distinção e oposição, as identidades sociais.

O elemento que consubstancia este processo é o conceito de fronteira. As fronteiras são marcadas porque os grupos interagem com outras entidades das quais querem ser distinguidas. A forma como estas fronteiras são marcadas depende da especificidade da comunidade em questão. Algumas, como as fronteiras físicas ou administrativas, podem estar contidas na lei; outras podem ser linguísticas, raciais ou religiosas. No entanto, nem todas as fronteiras são imediatamente aparentes; elas podem existir apenas nas cabeças dos seus membros, constituindo o que Cohen denomina de "fronteiras simbólicas".

\section{Espaços Públicos}

O espaço público surge, no contexto deste trabalho, como um conceito central e orientador da pesquisa, na medida em que ele é o palco onde os actores sociais interagem e constroem as representações face aos outros. O espaço (seja público ou privado) surge, tal como salienta J. Remy (1992), como uma mediação indispensável, onde se formam as concretizações particulares e se exprimem de maneira diferente as estruturas sociais e culturais. Não deve ser pois, uma variável acessória, uma construção artificial a que apenas se recorre para contextualizar a acção social. Ela pode ter um carácter explicativo importante e deve aparecer, fundamentalmente, como um suporte mediador das práticas e das representações sociais, um lugar privilegiado onde se desenvolvem e manifestam ambiguidades, contradições e heterogeneidades sociais, no fundo onde se estabelecem relações concretas entre os actores sociais.

Os espaços de co-presença seleccionados para análise têm em comum a sua condição urbana ou péri-urbana e o facto de todos serem espaços públicos. Esta conjugação entre carácter público dos espaços e a sua localização urbana tem trazido algumas dificuldades, no campo disciplinar da sociologia urbana, relativamente à construção do conceito de espaço público. De facto, a sua elaboração, ao contrário do que se passou com a filosofia política ou com as ciências da comunicação ${ }^{7}$, foi mais controversa por se ter privilegiado a sua associação com a análise dos espaços residenciais e a consequente diversidade de culturas urbanas e modos de apropriação do espaço aí presentes. O acento dado a esta associação fez emergir uma série de estudos que viam o espaço público apenas como um prolongamento do espaço privado do habitat, ou ainda como um espaço colectivo apropriado por uma comunidade que o bairro deveria traduzir, através da sua escala, da sua estrutura, da sua forma e da própria vizinhança. De há uns anos a esta parte, a noção de comunidade foi afastando-se progressivamente do conceito de espaço público, mas as duas grandes referências de origem deste último mantiveram-se, a saber: espaço de comportamentos e espaço de comunicação, entre lugares e opiniões. Aquela concepção mais restrita de espaço público foi dando lugar, a par das transformações urbanas e sociais, a uma noção mais abrangente.

Isaac Joseph $(1991,1998)$ é um dos autores que tem concentrado a sua atenção numa visão mais alargada de espaço público que vai desde a rua, até ao centro comercial, passando por estações de metro ou de comboio ou mesmo por parques de estacionamento. No fundo, tratam-se de espaços acessíveis a todos que pressupõem "(...) encontros socialmente organizados por rituais de exposição ou de inibição que pouco se relacionam com a convivialidade inerente à vida de bairro e das relações de vizinhança" (1998: 52). Tratam-se de espaços públicos específicos que pressupõem diferentes escalas de envolvimento dos actores entre si e com o próprio espaço.

No contexto deste trabalho optou-se, pois, pela noção mais alargada de espaço público, ligada a "espaço para a acção" na relação dialéctica entre as condições da sua produção e as formas de apropriação privilegiadas pelos seus utentes. Esta noção é também profícua por permitir analisar as relações sociais entre desconhecidos, sem ter necessariamente que significar solidariedades e proximidades nas relações que se estabelecem. No fundo, apesar da visibilidade e acessibilidade a todos os seus possíveis utentes, os espaços públicos tendem a acolher interacções específicas, marcadas pela impessoalidade e imprevisibilidade das relações que se estabelecem.

\footnotetext{
${ }^{7}$ Nestes campos disciplinares o termo espaço público designa uma cena de aparição pública onde a diversidade de opiniões se exprime, evocando o dispositivo democrático, regido pelo prazer "sociável" de falar livremente em grupo (Cf. Hannah Arendt e de J. Habermas).
} 
Mas este carácter anódino não significa uma permanente mutabilidade dos actores sociais em presença, nem dos usos aí praticados, uma vez que os espaços públicos podem gerar dinâmicas quotidianas, marcadas estas pelo carácter relativamente ritualizado das acções. E é, precisamente, o reconhecimento destas especificidades que fazem dos espaços públicos um instrumento importante e profícuo de coesão social e material da cidade, quando são levados em conta na sua produção, por um lado, parâmetros que tendem a produzir efectivas potencialidades de uso e, por outro lado, dispositivos que permitem uma leitura unitária da cidade existente.

\section{Apropriação do Espaço Público}

Verifica-se, pois, que o espaço é um efeito construído pelas nossas utilizações, é um espaço de saberes que orientam as actividades que aí se desenvolvem. É esta sua qualidade que permite aos utilizadores saber se se encontram numa situação normal ou num contexto de alarme. As sequências de actividades no espaço público comportam, assim, uma exigência implícita de interpretação imediata, o que pressupõe, da parte dos seus utentes, determinadas formas de se darem a ver sobre o território em causa.

A questão da visibilidade nos espaços públicos é um tema recorrente quando se procura analisar as formas de apropriação destes territórios particulares e a sua repercussão na construção das representações sociais. A visibilidade de determinadas populações no espaço público - expressão pública de traços culturais distintivos - pode ser perturbadora dos usos que outros grupos sociais gostariam de imprimir a estes espaços, tendo como consequência o estabelecimento de demarcações no território, ou seja, fronteiras materiais e simbólicas que se manifestam por detalhes concretos e constituem verdadeiros índices de segregação.

Para Hervé Le Bras (1997) "o habitante das cidades tornou-se num tipo de convidado no espaço público urbano", onde deve comportar-se de maneira cada vez mais codificada. Para este autor a questão já não reside tanto na forma como a hospitalidade permite aos indivíduos reconhecerem-se mas, sobretudo, na maneira como a hospitalidade urbana, traduzida em "gigantescos espaços de recepção", mantém à distância e domina cada vez mais um conjunto de pessoas sem pertenças definidas. Constata-se, pois, como salienta I. Joseph, “(...) que o direito de visita não é ainda um direito de cidadãos soberanos, mas é já mais do que o direito dos membros de uma comunidade que teriam de exibir os signos da sua identidade ou os índices da sua pertença" (1998: 67) ${ }^{8}$.

Sendo um dado adquirido que o mesmo espaço pode acolher simultânea e sucessivamente utilizadores diferentes, fica, pois, por saber, face à segmentação dos usos do espaço público, como definir a qualidade de um espaço que acolhe actividades e públicos diversos, tornando possível a sua coexistência.

Já tínhamos mencionado duas das condições necessárias para um espaço público urbano

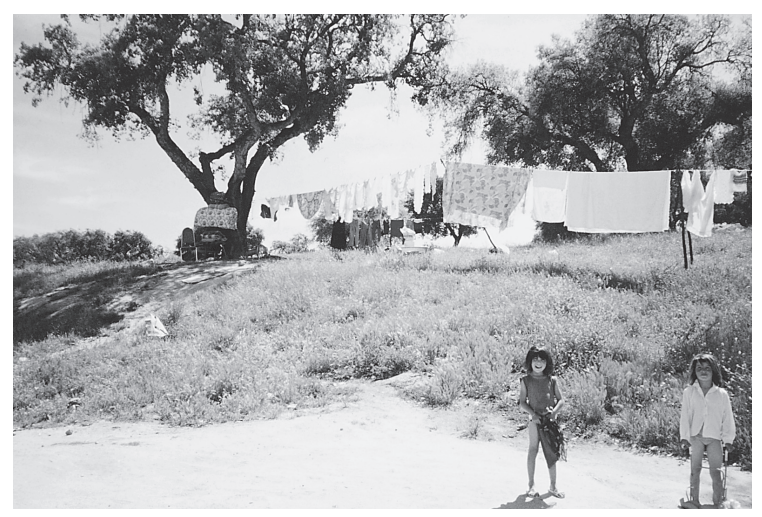

Foto de Alexandra Castro

preencher a função de coesão social e material da cidade e permitir a sua apropriação por parte dos habitantes. Falta, no entanto, referir o papel da norma na utilização do espaço e a sua interferência ao nível da convivialidade urbana. Desde logo, uma questão que se coloca refere-se às formas de pensar o conjunto de dispositivos (operadores ou programas) que elaboram ou instituem normas de uso e disposições (competências sociais e técnicas) que ajustam ou redefinem estas normas de uso.

Convém salientar que a apropriação de um determinado espaço nem sempre se faz em conformidade com um modelo. A distinção em relação à norma é também uma forma de apropriação, ainda que nem sempre seja fácil identificar e avaliar a partir de que momento a "trans-

\footnotetext{
${ }^{8}$ Para um maior aprofundamento da problemática dos espaços públicos sugere-se a leitura dos artigos de Matias Ferreira, V. (2000) e Matias Ferreira, V.; Castro, A. (2000).
} 
gressão" sistemática obedece a um contra-modelo. Temos, assim, de ter em conta como nos diz Raymond, referindo-se aos espaços de habitat, que existe "(...) un décalage entre l'existence de modèles d'appropriation, et le caractère plus ou moins permissif de l'habitat vis-à-vis de ces modèles d'appropriation. Par ailleurs tous les habitants ne développent pas leur compétence à un degré égal (...) tous ne l'intègrent pas de la même façon à leur mode de vie" (1976: 79).

Retomando a definição de espaços públicos sugerida por Richard Sennett (1979) de lugares de "visibilidade" onde se desenvolvem modos particulares de sociabilidade, importa reflectir sobre o papel da norma implícita ou explícita nas formas de gestão das aparências e das tensões entre exposição e observação. Com isto queremos analisar até que ponto a normatividade presente na utilização dos espaços públicos interfere nas formas do sujeito se apresentar sobre este território particular.

No caso da inexistência de regras implícitas na utilização dos espaços públicos podemos interrogar-nos se as práticas sociais observadas nos lugares públicos serão o resultado de uma representação colectiva e simbólica do domínio público, ou se estas práticas traduzirão uma "aprendizagem colectiva histórica" do modo de vida urbano. Uma abordagem à coexistência sócio-espacial poderá trazer alguns contributos de problematização destas questões.

\section{As Normas Implícitas ou Explícitas de Utilização do Espaço Público}

As pesquisas que se têm centrado sobre a coexistência de grupos sociais muito diversificados num mesmo espaço, constatam a dificuldade de gestão das relações sociais entre grupos. Para Pinçon (1981) este fenómeno relaciona-se, sobretudo, com o facto da proximidade física não corresponder a uma proximidade social e de, na ausência de um grupo dominante, se assistir ao confronto de práticas e valores diversificados consoante os grupos que procuram impor-se. Muitos conflitos estão na origem de incompreensões alimentadas por concepções e práticas diferenciais do espaço público e do espaço privado, por comportamentos julgados naturais por uns e reprovados por outros. É neste sentido que podemos colocar como hipótese que a familiaridade dos ciganos com os espaços públicos conduzem-nos a tomar determinadas atitudes, fruto de uma aprendizagem colectiva de apro- priação destes espaços, ligada ao modo de vida itinerante, que muitas vezes entra em conflito ou em contradição com a representação simbólica de outros grupos face à legitimidade de usos inerente à qualidade destes espaços.

$\mathrm{O}$ confronto entre representações e práticas diferenciadas do/no espaço público não pressupõe, no entanto, a existência e perpetuação de determinados conflitos. Para Mayol (1980) os conflitos podem ser minimizados, ao nível dos comportamentos, por aquilo a que o autor chamou de "conveniência", ou seja, um compromisso estabelecido por cada indivíduo, através de uma renúncia à anarquia dos impulsos individuais, no sentido de prestar um contributo à vida colectiva e daí retirar benefícios simbólicos diferenciados no tempo.

A literatura anglo-saxónica, nomeadamente através dos trabalhos de Herbert e Johnston (1976) propõe um modelo clássico que dá conta das modalidades de relações entre grupos em presença. Quando o grau de diferenciação é fraco e a assimilação é possível sem uma grande alteração das especificidades de cada grupo, assiste-se a uma tendência de dispersão. No caso contrário, observa-se uma tendência à concentração espacial por um certo período de tempo ("colónias") ou de forma permanente, produzindo-se enclaves ou guetos.

Alguns autores têm procurado no conceito de hospitalidade uma forma de abordar as questões ligadas ao desenvolvimento da precaridade e à institucionalização da vida quotidiana, já que se inscreve numa reflexão sobre a crise social e sobre a exclusão. Trata-se de um conceito que está intimamente ligado à história urbana e à produção de fronteiras.

A hospitalidade implica partilha de espaço e reconhecimento de pluralismo cultural. Trata-se de um exercício perturbador, custoso e cansativo que exige, por um lado, alguma organização e, por outro, o reconhecimento do hospedeiro "como alguém que traz qualquer coisa" e não apenas como alguém que interfere. Mas esta reciprocidade impõe, na grande maioria das situações, um trabalho de mediação, já que uma das formas modernas da hospitalidade é a passagem da reciprocidade à não reciprocidade, com consequências inevitáveis ao nível das relações estabelecidas. De facto, a hospitalidade unilateral é portadora de tensões e de ressentimentos quer daquele que recebe, quer do que é recebido. É este aspecto moderno da hospitalidade que conduz, segundo Olivier Schwartz (1997) à transposição desta problemática inter-individual para 
as instituições, para os territórios e para as entidades políticas.

\section{Síntese dos Resultados}

A primeira conclusão retirada deste trabalho prende-se com a variação mínima das representações e das práticas de sociabilidade com a comunidade cigana ao longo dos quatro espaços de co-presença. Por essa razão, optámos por apresentar os dados de uma forma horizontal, privilegiando um olhar de conjunto, sem nunca pôr de lado a singularidade das interacções desenvolvidas em cada um dos espaços.

\section{Representações Sobre os Ciganos}

Transversal aos quatro estudos de caso realizados está uma representação do cigano que assenta, sobretudo, em dimensões neutras e dimensões negativas. Se, num primeiro momento, os entrevistados identificam os elementos desta comunidade através de elementos físicos distintivos (cor da pele, traços fisionómicos, forma de vestir) ou de modos de expressão particulares (sotaque, forma de estar), num segundo momento introduzem aspectos essencialmente negativos, relacionados com o "comportamento" dos ciganos. E é, precisamente, através destes aspectos que se constrói, de uma forma definitiva, a fronteira que distingue os ciganos dos não-ciganos. Subjacente a este facto está a constatação de que a assimilação dos ciganos é ilusória: apesar de poderem não parecer "ser ciganos", os seus gestos e atitudes na interacção com os outros colocam-nos inegavelmente na comunidade a que se julgava não pertencerem.

As características apontadas como definidoras da comunidade cigana parecem implicar, nos discursos dos entrevistados, elementos como o fechamento ao exterior, a união e a dificuldade de integração. Na interacção social com outros grupos estas características manifestam-se por um conjunto de traços negativamente conotados como a agressividade, a arrogância e a presença do grupo. Estes comportamentos são vistos como ameaçadores, não apenas pela impermeabilidade da comunidade cigana mas também pela presença e reacção conjunta a qualquer atitude exterior que possam (por vezes, indevidamente) tomar como hostil. Por outro lado, a associação tradicional dos ciganos ao comércio parece sem- pre implicar aquilo a que alguns entrevistados chamam de "atitudes duvidosas", onde o engano e a mentira ocupam um lugar de destaque.

As dimensões positivas da representação dos ciganos aparecem apenas em dois contextos: no Bairro da Boavista e no Hospital Garcia de Orta. Estas dimensões positivas decorrem da natureza das interacções sociais que se desenvolvem no interior de cada um destes espaços. Assim, no Bairro da Boavista, onde a proximidade dos entrevistados é continuada e quotidiana, surgem características como a solidariedade e a "alegria" dos ciganos - características que apenas podem ser conhecidas por quem tem mais do que um contacto superficial com esta comunidade. Por outro lado, os traços positivos referidos pelos entrevistados do Hospital Garcia de Horta (coesão social e união familiar) constituem características desejáveis na perspectiva dos profissionais de saúde, que assistem demasiadas vezes ao abandono a que os doentes são votados pelas suas famílias. No entanto, em ambos os casos, os traços positivos atribuídos aos ciganos têm como contraponto atitudes que tornam estes indivíduos problemáticos aos olhos dos entrevistados: se é verdade que os ciganos são "alegres", também é verdade que as suas festas (barulhentas e prolongadas no tempo) perturbam os restantes habitantes do bairro; se é verdade que os ciganos se caracterizam pela solidariedade e união familiar, também é verdade que esta coesão adquire uma natureza intimidante e activamente hostil perante os técnicos de saúde e funcionários do hospital.

A imagem tendencialmente negativa da comunidade cigana não é uma construção recente, ainda que os seus contornos se tenham transformado num passado próximo. De uma forma geral, as representações sobre os ciganos ligadas à infância dos entrevistados fazem apelo a uma presença intermitente de grupos nómadas, caracterizados essencialmente pela pobreza e pelo receio das populações relativamente à integridade dos seus bens. Enraizada nos discursos está sempre a associação desta comunidade à eventualidade de roubos e enganos, associação essa que, como vimos, se mantém no presente. Todavia, a imagem actualmente preponderante sobre os ciganos já não menciona a pobreza como elemento caracterizador. Pelo contrário, são frequentes as referências à ostentação de riqueza e as insinuações de negócios ilícitos, ligados sobretudo ao tráfico de droga. Poder-se-á, por isso, concluir que a imagem que os entrevistados têm dos ciganos se afastou de um quadro de exclusão 
social total (nómadas ou semi-sedentários a habitarem bairros degradados, sem fontes de rendimento regulares, sem assistência médica, etc.) através da integração recente desta comunidade no sistema institucional (com a implementação de medidas como o Rendimento Mínimo Garantido ou o acesso ao Sistema Nacional de Saúde) e no sistema territorial (com a inclusão dos ciganos nas políticas de habitação social). Apenas no estudo de caso do terreno de estacionamento de Azeitão nos deparamos com a persistência da imagem dos ciganos como excluídos de todos os "sistemas sociais básicos", já que o contacto inter-étnico se dá sobretudo com os grupos nómadas que percorrem as localidades em acampamentos temporários.

A racialização da diferença está presente em todos os estudos de caso, já que a maioria dos entrevistados atribuem uma linha de causalidade entre a pertença étnica à comunidade cigana $\mathrm{e}$ determinados traços comportamentais e culturais. Embora nem todos os inquiridos utilizem o termo "raça", podendo substituí-lo pela palavra "etnia" (menos conotada negativamente), a verdade é que existe um processo de reificação da imagem do grupo. Mesmo no caso do Hospital, cujos entrevistados se encontram numa categoria socioprofissional elevada, com maior acesso à informação e, portanto, mais aptos a construírem uma visão relativizadora destas questões, encontramos um processo de racialização implícita. Este processo, comum a todos os estudos de caso, tem como consequência o facto de o cigano ser sempre pensado como parte de um grupo, caracterizado pelo fechamento e pela extrema união dos seus elementos, e não como um indivíduo isolado. A admissão, por parte dos entrevistados, da existência de ciganos "menos problemáticos" (mais integrados na sociedade, menos conflituosos, mais "normalizados") tem subjacente a premissa de que essa é uma excepção sem grande significado que não vem alterar a imagem que fazem desta comunidade, como se aos ciganos apenas se concedesse uma existência grupal, e nunca individual.

Este processo de reificação da diferença, de tomar o todo pela parte, encontra ainda expressão na forma pela qual os entrevistados percepcionam a eventual heterogeneidade da comunidade cigana. As distinções mais referidas em todos os estudos de caso apontam para variações económi- cas no interior desta comunidade (ciganos ricos/ciganos pobres) e para diversas dimensões que reenviam para a integração e assimilação relativa dos seus elementos (a sedentarização, a escolarização, a "normalização" na forma de vestir, etc). Estas distinções, que a maioria dos entrevistados reconhecem ser superficiais, constituem porventura o reflexo do desinteresse esmagadoramente afirmado relativamente a este grupo - em 46 entrevistados, apenas 6 manifestaram curiosidade pela forma de vida dos ciga$\operatorname{nos}^{9}$. Por seu turno, este desinteresse manifesta-se no reduzido contacto que os entrevistados têm com a comunidade cigana: para a generalidade dos entrevistados, o contacto com a comunidade cigana não é espontâneo nem o resultado da sua vontade. Pelo contrário, ele ocorre por imperativos de ordem diversa: vizinhança no bairro, proximidade física nos lugares de venda da feira, existência de utentes ciganos no hospital. A inter-acção inter-étnica desenvolvida nos quatro estudos de caso é marcada pela sua delimitação vincada no espaço e no tempo, não se prolongando noutros contextos para além daqueles que foram investigados.

Quando contraposta com outros grupos minoritários, a etnia cigana surgiu sempre negativamente valorada. Fossem indianos ou negros, em todos os estudos de caso os hetero-referentes foram apresentados como menos problemáticos e mais integrados. A relação dos ciganos com os não-ciganos parece envolver uma complexidade de difícil resolução em todos os contextos estudados, ainda que essa complexidade tome diferentes formas nos vários espaços de co-presença. Assim, no Bairro da Boavista, onde a facilidade de coabitação é o critério principal para a comparação, a comunidade de origem africana foi caracterizada pela maior abertura e facilidade de convivência; na Feira de Cascais, onde a eventual conflitualidade e o incumprimento de algumas regras básicas constituem problemas graves, os indivíduos de origem indiana foram apresentados como mais "pacíficos" e "cumpridores"; finalmente, o espaço do hospital, onde as regras de funcionamento colidem com a presença impositiva e grupal dos ciganos, os indianos e negros surgiram como sendo de trato mais fácil devido ao facto de serem mais "individualistas" e "menos ligados ao grupo".

${ }_{9}^{9}$ De entre estes 6 casos, 2 reportam-se ao estudo de caso no Bairro da Boavista, 3 pertencem ao estudo de caso realizado no Hospital e 1 a uma utente da Feira de Cascais. 


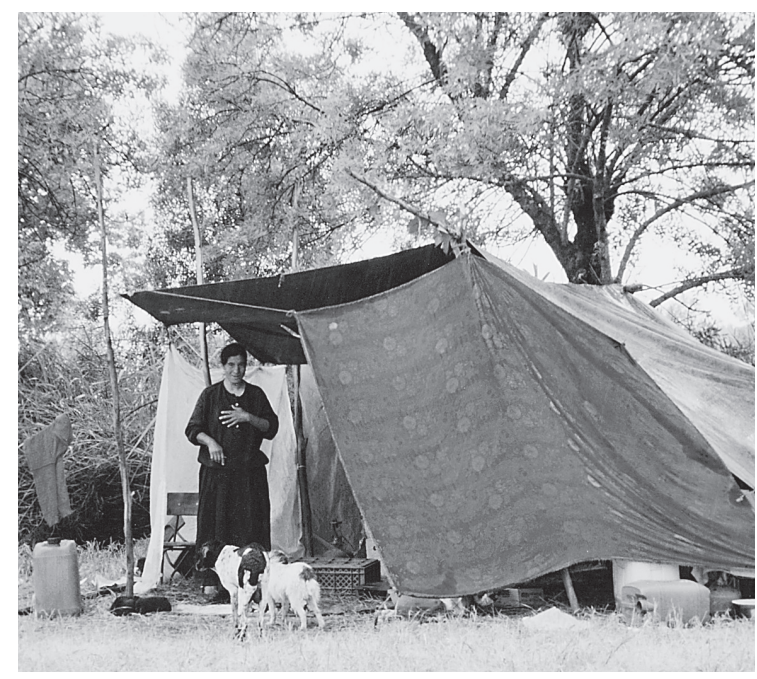

Foto de Alexandra Castro

\section{Apropriação do Espaço}

O presente trabalho permite concluir que as singularidades dos diferentes grupos sociais tomam forma no espaço, concretizando as heterogeneidades em modos de apropriação do espaço diversas e eventualmente conflituais. De facto, o confronto cultural (materializado em diferentes modos de usar e estar no espaço) parece constituir o momento fundamental da percepção dos limites das várias identidades sociais em co-presença.

Nesse sentido, o confronto com os ciganos nos quatro espaços estudados traduz-se na constatação de dois aspectos fundamentais: a sua extrema visibilidade nos espaços públicos e o seu auto-centramento na apropriação do espaço. Estes dois aspectos fundamentais desdobram-se em diversas características negativamente conotadas pelos entrevistados: a falta de higiene que parece sempre acompanhar a permanência dos ciganos nos espaços estudados; o carácter impositivo da presença do grupo; a "incivilidade" demonstrada na utilização dos espaços comuns.

Somente no estudo de caso do Bairro da Boavista surgiu uma dimensão positiva da apropriação do espaço pelos ciganos, decorrente da proximidade quotidiana entre os indivíduos. Assim, foi referido que existem ciganos tão "limpos" e "organizados" como outras pessoas quaisquer, proprietários de casas onde não impera a sujidade ou desorganização que caracteriza, segundo os entrevistados, a forma pela qual a comunidade cigana se apropria do espaço da habitação. Mais uma vez, reencontramos um processo de racialização, pelo qual os comporta- mentos e cultura cigana são reificados num conjunto de imagens negativas, sendo os comportamentos individuais positivamente valorados considerados excepções sem grande importância.

Se fosse necessário resumir a impressão geral da presença nos ciganos nos quatro estudos de caso realizados, a expressão adequada seria "desrespeito". Desrespeito pelos outros moradores do bairro, manifestado pelo barulho das festas intermináveis, pela sujidade e pelos actos de vandalismo nos espaços comuns; desrespeito pelos habitantes das imediações dos terrenos de estacionamento, através da falta de higiene dos acampamentos e pelas solicitações constantes de apoio (água, alimentos, etc); desrespeito pelos outros vendedores da feira, expresso na ignorância da delimitação camarária dos espaços de venda e, mais uma vez, pela falta de higiene; desrespeito pelo técnicos de saúde e utentes do Hospital, com a desconsideração sistemática das suas regras de funcionamento.

Este "desrespeito" implica, sobretudo, o desprezo por regras de qualquer natureza. Se há um elemento transversal aos quatro estudos de caso, é precisamente o facto de os ciganos ignorarem, por vezes de uma forma ostensiva, todas as regras: desde as regras camarárias relativas à Feira, passando pelas regras de funcionamento do Hospital, até às mais elementares regras implícitas de convivência com os outros. Podemos, assim, afirmar que as representações sobre a apropriação do espaço por parte da comunidade cigana se organizam em torno da ideia de "transgressão". Resta saber de que forma os entrevistados lidam não apenas com as "transgressões", mas também e sobretudo com os elementos de uma comunidade que, como vimos, é muito negativamente representada pela totalidade dos inquiridos.

\section{Interacções entre Ciganos e Não-Ciganos}

Em todos os estudos de caso realizados, a proximidade física entre ciganos e não-ciganos nos espaços de co-presença é caracterizada pela manutenção de uma distância social que os entrevistados consideram ser "de segurança". Esta distância surge como a resposta necessária à tensionalidade inerente a este confronto cultural. A conjugação do carácter impositivo da presença do grupo cigano, do seu auto-centramento na apropriação do espaço e do desrespeito pelas normas, transforma a interacção com os ciganos em 
momentos particularmente perturbadores, marcados pelo equilíbrio instável e pela possibilidade de eclosão de conflitos.

A permissividade constitui, assim, o elemento central das interacções com os ciganos. Todos os entrevistados são unânimes em reconhecer o tratamento de excepção concedido à comunidade cigana. Mais do que a tradicional discriminação étnica negativa, reencontramos nos quatro estudos de caso a denúncia de práticas discriminatórias positivas. A transgressão constante praticada pelos ciganos nos diversos espaços sociais investigados tem como resposta o silêncio e o consentimento, num acordo tácito de

\section{Bibliografia}

BELL, C.e HOWARD N. (1971) Community studies. An introduction to the sociology of the local community, Londres, George Allen \& Unwin, 1982, $4^{\mathrm{a}}$ edição.

COHEN, A. (1982) Belonging. Identity and Social Organisation in British Rural Communities, Manchester, Manchester University Press.

COHEN, A. P.(1985) The Symbolic Construction of Community, Londres, Routledge, 1989.

GOLDBERG, D. T. (2000) "Racial Knowledge" in BACK, L. e SOLOMOS, John (eds.) Theories of Race and Racism, Londres e Nova Iorque, Routledge, Readers in Sociology.

GUSFIELD, J.R.(1975) Community: a critical response, Oxford, Basil Blackwell.

HERBERT, D.T.; JOHNSTON, R.J. (1976) Social areas in cities, Londres, Willey.

JOSEPH, I.(1991) "Voir, Exposer, Observer" in L' espace du public, les compétences du citadin, Colloque d'Arc-et-Senans, nov-1990, Plan Urbain-Éditions Recherches.

LE BRAS, H. (1997) Ville et hospitalité, Textos de síntese do Seminário, Paris, Fondation Maison des Sciences de l'Homme, Plan Construction et Architecture.

MACHADO, F. L. (2000) "Os Novos Nomes do Racismo: Especificação ou Inflação Conceptual?", Sociologia Problemas e Práticas, $\mathrm{n}^{\circ} 33$

MARQUES, J. F. (1997) "Ainda Podemos Falar de 'Raças'? A 'Raça' Enquanto Conceito Sociológico" in $O$ que é a raça? Um debate entre a Antropologia e a Biologia, Lisboa, Espaço OIKOS.

MATIAS FERREIRA, V. (2000) "Cidade e Democracia. Ambiente, Património e Espaço Público", Cidades. Comunidades e Território, $\mathrm{n}^{\circ}$ 1, Lisboa, CET.

MATIAS FERREIRA, V.; CASTRO, A. (2000) "Espaços Públicos e Verde Urbano em Lisboa. Um Estudo de Caso não-confrontação. Esta permissividade geradora de discriminação positiva não é guiada por um qualquer princípio de boa-fé, mas pelo medo de represálias e conflitos.

Por outro lado, os ciganos parecem manipular a permissividade com que são tratados, utilizando-se do estigma que lhes está associado e da presença do grupo como armas de persuasão e intimidação. A distância social existente entre ciganos e não-ciganos é aprofundada e consolidada por um abismo onde se conjuga o desconhecimento, a mitificação e o medo. Nas palavras de um entrevistado, "Eles por serem uma etnia julgam que têm todos os direitos".

sobre Ambiente Urbano em Lisboa", Cidades. Comunidades e Território, $\mathrm{n}^{\circ}$ 1, Lisboa, CET.

MAYOL, P. (1980) L'invention du quotidien II - Habiter, Paris, UGE.

MOSCOVICI, S. (1984) "The phenomenon of social representations" in FARR, Robert M. e Serge MOSCOVI (eds) Social Representations, Cambridge, Cambridge University Press, (3-69).

MOSCOVICI, S. (1988) "Notes towards a description of social representations", European Journal of Social Psychology, vol. 18 (211-250).

PINCON, M. (1981) Cohabiter groupes sociaux et modes de vie dans une cité HLM, Paris, Plan Construction.

NISBET, R. (1966) La tradition sociologique, Paris, PUF, 1984.

RAYMOND, H. (1976) «Quelques aspects théoriques et pratiques de l'appropriation de l'espace» in KOROSEC-SERFATY (ed.), Appropriation de l'espace, Actes de la conférence de Strasbourg, Louvain-la-Neuve.

REMY, J. VOYE, L. (1992) La ville: vers une nouvelle definition?, Paris, L'Harmattan.

SENNET, R.(1979) Les tyrannies de l'intimité, Paris, Seuil.

SCWARTZ, O. (1997) Ville et hospitalité, Textos de síntese do Seminário, Paris, Fondation Maison des Sciences de l'Homme, Plan Construction et Architecture.

VALA, J. (1993) "As representações sociais no quadro dos paradigmas e metáforas da psicologia social", Análise Social, vol. XXVIII, 123-124 (887-919).

VALA, J. (ed) (1999) Novos Racismos. Perspectivas Comparativas, Oeiras, Celta Editora.

WORSLEY, P.(1970) "A comunidade na sociedade moderna" in Introdução à Sociologia, Lisboa, Pub. D. Quixote, $1977,3^{\text {a }}$ edição. 